\section{Miocarditis por clozapina}

\section{Sr. Director:}

La población psiquiátrica presenta una serie de características especiales que les predisponen a cuadros infecciosos: la institucionalización, la elevada frecuencia de alcoholismo (inmunosupresor), el uso de drogas por vía parenteral (riesgo de infección por VIH, infecciones derivadas de las venopunciones como endocarditis) hacen que con frecuencia la presencia de fiebre nos lleve a considerar a estos pacientes como de riesgo para infecciones atípicas. Esto nos puede llevar a pasar por alto otras circunstancias como los posibles efectos secundarios de la medicación psiquiátrica, con unas consecuencias potencialmente graves. Paciente varón de 26 años, ingresado por un brote psicótico agudo severo en el Servicio de Psiquiatría. Ante la ausencia de respuesta a risperidona se inicia tratamiento con clozapina a dosis crecientes hasta $175 \mathrm{mg} /$ día. En el decimoséptimo día de inicio del fármaco, el paciente comienza con fiebre y disnea. En la exploración física destacaba taquipnea, taquicardia y crepitantes bilaterales. En las pruebas complementarias presentaba leucocitosis $\left(16.000 \mathrm{cel} / \mathrm{mm}^{3}\right)$ con eosinofilia $(11 \%)$ e insuficiencia respiratoria tipo I. Los enzimas cardíacos (troponina, $\mathrm{CK}, \mathrm{LDH}$ ) fueron normales. El electrocardiograma mostraba taquicardia sinusal sin datos de isquemia. En la radiografía de tórax presenta patrón intersticial así como un pequeño derrame pleural bilateral. Se realiza ecocardiografía transtorácica objetivándose ventrículo izquierdo de dimensiones normales, con función sistólica disminuida (fracción de eyección 45\%), sin alteraciones valvulares significativas ni imágenes sugestivas de vegetaciones ni derrame pericárdico. Con la sospecha diagnóstica de miocarditis por clozapina se suspendió dicho fármaco y se inició tratamiento diurético e inhibidores de la enzima convertidora de la angiotensina (IECA). En 24 horas el paciente mejoró clínicamente, con desaparición de la fiebre y la insuficiencia respiratoria y normalización analítica y radiológica. En el ecocardiograma a las 72 horas de la suspensión del fármaco se constató normalización de la función cardiaca.

La clozapina es un nuevo antipsicótico, una dibenzodiazepina de segunda generación de utilidad en el tratamiento de aproximadamente el $30 \%$ de pacientes con esquizofrenia que no responden al tratamiento convencional (1). Sus efectos secundarios más conocidos incluyen: sedación, hipersalivación, ganancia de peso, cambios electroencefalográficos, crisis comiciales y su efecto más temido es la agranulocitosis (0,9\% de pacientes) (2). Se han comunicado otros efectos secundarios igualmente graves pero menos conocidos (3). Se han reportado, aunque con menor frecuencia aún, efectos secundarios cardiovasculares, entre ellos: miocardiopatía, pericarditis y miocarditis (4). La miocarditis expresa la inflamación del miocardio. El diagnóstico de certeza exige la demostración anatomopatológica de un infiltrado inflamatorio con focos de necrosis o degeneración miocítica no asociado a isquemia coronaria. Aunque la causa de miocarditis es desconocida en la mayoría de los casos, se la ha relacionado con una gran variedad de infecciones, enfermedades sistémicas, drogas y sustancias tóxicas. Entre las sustancias tóxicas mas frecuentemente asociadas, las más prevalentes corresponden a antraciclinas, cocaína, etanol, anfetaminas y litio (5). La asociación de miocarditis por clozapina ocurre en menos del $0.1 \%$ de pacientes tratados, entre 15 días y 1 año del inicio del tratamiento como en el caso del cuadro en nuestro paciente. Hasta el momento, hay documentados menos unos 100 casos de miocarditis por clozapina en la literatura según una revisión reciente (4). El mecanismo que la produce es desconocido, pero se ha invocado un mecanismo de hipersensibilidad, y en la biopsia miocárdica se ha confirmado anatomopatológicamente y observado infiltración por eosinófilos (7), concordando con eosinofilia en la mayoría de los casos descritos en la literatura así como el que aportamos, lo que indica una posible hipersensibilidad mediada por $\operatorname{Ig} \mathrm{E}(8)$. Se ha asociado con una importante mortalidad (hasta el $30 \%$ ), ya que como la miocarditis de cualquier origen al comportarse de forma insidiosa, el retraso diagnóstico puede comportar un desenlace fatal. De hecho, algunos estudios necrópsicos sugieren que la miocarditis de diversa causa, puede ser la causa de hasta un $20 \%$ de las causas de muerte súbita en menores de 40 años (9). Algunos pacientes han sido tratados de forma satisfactoria con corticoides (7). Otros fármacos utilizados en psiquiatría, han sido relacionados con miocarditis o miocardiopatía, (otros antipsicóticos, litio, clorpromacina, flufenacina y haloperidol), aunque las evidencias para asegurar estas asociaciones son de momento insuficientes (10). La toxicidad cardiovascular relacionada con clozapina ha sido documentada, estando contraindicado su uso en pacientes con cardiopatía previa. Puede sin embargo obviarse esta posibilidad tóxica en pacientes jóvenes sin cardiopatía conocida, siendo necesario distinguir los síntomas de esta afección de aquellos derivados de los cambios rápidos en la dosificación del 
fármaco como la taquicardia (que ocurre en el $25 \%$ de los pacientes), letargia e hipotensión ortostática. En definitiva, como aportamos en nuestro caso, los pacientes psiquiátricos deben ser evaluados de forma especial cuando tienen complicaciones orgánicas. Ante la presencia de insuficiencia respiratoria y fiebre en pacientes psiquiátricos, se deben considerar los fármacos. En pacientes a tratamiento con clozapina deben considerarse los posibles efectos secundarios cardíacos, sobre todo en presencia de disnea u otros síntomas de origen cardíaco.

\section{Martínez Rey, I. Villamil Cajoto, M. Rodríguez Framil, S. Tomé Martínez de Rituerto, J. A. Torre Carballada}

Servicio de Medicina Interna. Hospital Clínico Universitario. Santiago de Compostela. A Coruña

1. Nemeroff CB. Use of atypical antipsychotics in refractory depression and anxiety. J Clin Psychiatry 2005; 66 (Supl. 8): 13-21.

2. Miller DD. Review and management of clozapine side effects. J Clin Psychiatry 2000; 61: 14-7.

3. Gonzalo Eymin L, Max Andresen H, Jaime Godoy F, Gabriel Rada G. Síndrome neuroléptico maligno y poliserositis en paciente usuaria de clozapina: una asociación infrecuente. Rev Med Chile 2005; 133: 12251228.

4. Wehmeier PM, Heiser P, Remschmidt H. Myocarditis, pericarditis and cardiomyopathy in patients treated with clozapine. J Clin Pharmacy Therapeutics 2005: 30; 91-6.

5. Feldman AM, McNamara D. Myocarditis. N Engl J Med 2000; 343: 1388-98.

6. Merrill DB, Dec GW, Goff DC. Adverse cardiac effects associated with clozapine. J Clin Psychopharmacol 2005; 25: 32-41.

7. Pieroni M, Cavallaro R, Chimenti C, Smeraldi E, Frustaci A. Clozapine induced hypersensibility myocarditis. Chest 2004; 126: 1703-5.

8. Killian JG, Kerr K, Lawrence C, Celermajer DS. Myocarditis and cardiomyopathyassociated with clozapine. Lancet 1999; 354: 1841-5.

9. Drory Y, Turetz Y, Hiss Y, et al. Suden unexpected death in persons less than 40 years of age. Am J Cardiol 1991; 68: 1388-92.

10. Coulter DM, Bate A, Meyboom RH, Lindquist M, Edwards IR. Antipsychotic drugs and heart muscle disorder in international pharmacovigilance: data mining study. BMJ 2001; 322: 1207-9.

\section{Rabdomiolisis por gemfibrozilo en un paciente con hipotiroidismo inadvertido}

\section{Sr. Director:}

La rabdomiolisis (RML) es una forma grave de miopatía resultado de la lesión severa y la lisis del músculo esquelético. Clínicamente se define por la presencia de clínica muscular, elevación de CK sérica con valores 10 veces los normales y daño orgánico (fundamentalmente, insuficiencia renal) secundarios a la lisis celular muscular (1). La RML producida por fármacos hipolipemiantes es un hecho bien documentado (1-3) y se estima que puede ocurrir en el $0,1-0,5 \%$ de los casos $(2,3)$.

Gemfibrozilo (GFZ) es un hipolipemiante de la familia de los fibratos que ha sido implicado en la aparición de RML en pacientes a los que se les administró conjuntamente con estatinas (4) pero muy raramente cuando se utiliza en monoterapia (5).
Presentamos el caso de un paciente en tratamiento con GFZ que desarrollo un cuadro de RML que pudo verse favorecido por la presencia de un hipotiroidismo inadvertido.

Varón de 37 años, sin antecedentes de hipertensión arterial, diabetes mellitus, consumo de tóxicos o abuso enólico. Fumador hasta hacía 8 meses. Intervención antigua de fractura tibial. Ingresó en agosto de 2005 por presentar dolorimiento muscular, sensación de contractura, decaimiento, fatigabilidad fácil y sensación inespecífica de mareos, que habían comenzado meses atrás y que achacaba al inicio del tratamiento con GFZ (600 $\mathrm{mg}$ /día) que había empezado a tomar en marzo de 2005, al detectarse hipertrigliceridemia en un control analítico previo al inicio de dieta hipocalórica. Refirió que la clínica era progresiva y había llegado a resultar incapacitante, motivo por el que ingresó. Negó fiebre, tos, disnea, aparición de lesiones cutáneas o síntomas neurológicos. En la exploración física su estado general aparente era bueno. Índice de masa corporal $37 \mathrm{~kg} / \mathrm{m}^{2}$. Bien hidratado y perfundido. Coloración cutaneomucosa normal. No adenopatías palpables. Auscultación pulmonar y cardiaca, abdomen y extremidades sin hallazgos de interés. Exploración neuromuscular, incluyendo fuerza, sensibilidad, reflejos osteotendinosos y marcha, normales.

En las exploraciones complementarias destacaba: urea 18 $\mathrm{mmol} / \mathrm{L}$, creatinina $135 \mu \mathrm{mol} / \mathrm{L}$, ácido úrico $452 \mu \mathrm{mol} / \mathrm{L}, \mathrm{CK}$ 1121 Ul/L (15-190), GOT 49 Ul/L, GPT 34 Ul/L, LDH 435 Ul/L. Ferritina $736 \mu \mathrm{g} / \mathrm{L}$ (30-400). Mioglobinemia 177,3 pg/l (6-85) y mioglobinuria 6,7 $\mu \mathrm{g} / \mathrm{l}(0)$. TSH $100 \mathrm{mU} / \mathrm{L}(0,27-4,2)$, T4 L, 3,8 $\mathrm{pmol} / \mathrm{l}(11,5-21)$. Anticuerpos antitiroglobulina positivos. El resto de determinaciones analíticas (hemograma, VSG, proteína C reactiva, estudio de coagulación, determinaciones séricas de glucosa, colesterol total, triglicéridos, proteínas totales, albúmina, bilirrubina total, bilirrubina directa, gammaglutamil transpeptidasa, fosfatasa alcalina, sodio, potasio, cloro, fósforo, cloro, calcio, hierro, transferrina, vitamina B12, ácido fólico, recuento de inmunoglobulinas, marcadores tumorales, factor reumatoide, ASLO y niveles de complemento, normales. Anticuerpos antinucleares, anti-DNA, anti-Sm, anti-RNP, anti-Ro, anti-La y antimúsculo liso, negativos. Niveles de cortisol, ACTH, cortisol libre urinario normales. Serología VHB, VHC, VIH, toxoplasma, CMV y VEB, negativos o sin seroconversión. Ecografía tiroidea normal.

Durante el ingreso se suspendió GFZ y se inició tratamiento hormonal sustitutivo tiroideo (levotiroxina $100 \mathrm{mcg} / \mathrm{día}$ ), con progresiva mejoría clínica y analítica (Tabla I). Seis meses después se encuentra asintomático.

\section{TABLA I}

EVOLUCIÓN ANALÍTICA

\begin{tabular}{lccc}
\hline & Diagnóstico & Al mes & A los 3 meses \\
\hline CK & 1.121 & 244 & 129 \\
TSH & 100 & 50 & 21 \\
T4 L & 3,8 & 8,7 & 10 \\
Triglicéridos & 164 & - & 136 \\
Urea & 50 & 42 & 46 \\
Creatinina & 1,5 & 1,1 & 1,0 \\
\hline
\end{tabular}

GFZ junto con clofibrato, fenofibrato, bezafibrato, etofibrato y binifibrato constituyen el grupo de los fibratos, que pertenecen al grupo terapéutico de los hipolipemiantes. Sus acciones fundamentales son la disminución de los niveles séricos de triglicéridos y de colesterol LDL y la elevación de los de colesterol HDL y su uso clínico es muy habitual en la prevención y el tratamiento de la enfermedad arteriosclerótica (6). Su mecanismo de acción 